\title{
CORROSÃO PELO SOLO DE AÇO GALVANIZADO NA REGIÃO DA CAMPANHA - RS
}

\author{
L. B. AVILA ${ }^{1 *}$, C. ERTHAL $^{1}$, L. M. RODRIGUES ${ }^{1}$ e S. N. DA SILVA ${ }^{2}$ \\ ${ }^{1}$ Universidade Federal do Pampa - Engenharia Química \\ ${ }^{2}$ Universidade Federal do Pampa - Engenharia de Energia \\ *E-mail para contato: luisabataglinavila@gmail.com
}

\begin{abstract}
RESUMO - Neste trabalho, foi analisado o grau de agressividade de solos coletados em seis municípios da Região da Campanha do RS, ao aço galvanizado, comumente utilizado em torres de linhas de transmissão, por ensaios acelerados e em campo. Para os ensaios em laboratório, adicionou-se $25 \%$ em massa de cinzas de carvão mineral aos solos e foi criado um defeito nos cupons enterrados. O ensaio em campo foi realizado na região central de Bagé onde uma amostra metálica foi parcialmente enterrada. Em todos os casos foram feitas aquisições de imagens e medidas de variação de massa e espessura. Foram observados indícios de corrosão localizada, de coloração levemente alaranjada, nos cupons enterrados nos solos de Candiota e Bagé. Nos ensaios acelerados, notou-se "corrosão branca", advinda do produto de corrosão que afeta superfícies galvanizadas, em todas as amostras, porém mais intensa nos solos de Candiota e Bagé. No ensaio em campo observou-se tanto corrosão branca quanto localizada da parte enterrada. Não foi observada variação significativa de massa e espessura no período estudado. Pode-se inferir que os solos estudados são agressivos ao aço galvanizado sendo o solo de Candiota o mais agressivo. Essa evidência possivelmente é devido às emissões da Usina Termoelétrica da região, as quais podem causar alterações físico-químicas nos solos tornando-os mais agressivos. Constatou-se também, que há corrosão, porém menos intensa, longe da fonte emissora.
\end{abstract}

\section{INTRODUÇÃO}

O termo "corrosão" pode ser definido como a reação do metal com os elementos do seu meio, na qual o metal é convertido a um estado não metálico (LALGUDI V. RAMANATHAN). Segundo Sandres (2004), este processo, além de apresentar danos à estrutura do material, causa problemas econômicos, uma vez que os custos, tanto diretos quanto indiretos, podem resultar em consideráveis desperdícios. Esses aspectos econômicos, de acordo com Gentil (1996), podem ser verificados nos mais diversos setores que utilizam estruturas metálicas enterradas como, por exemplo, torres de linhas de transmissão (LTs) e telecomunicações, tanques de armazenamento, oleodutos e gasodutos.

Na corrosão subterrânea, como ressalta Sandres (2004), apesar de o meio parecer seco sempre haverá determinada quantidade de água a qual atua como eletrólito para passagem de correntes, promovendo assim a aceleração do processo corrosivo. Além disso, o solo apresenta características que influenciam na velocidade de corrosão a um material metálico 
enterrado que, segundo Gentil (1996), são: presença de sais solúveis, presença de gases, pH, resistividade elétrica, potencial redox e presença de poluentes.

O potencial corrosivo de um solo pode ser agravado pela atividade industrial. Neste contexto, está incluída a geração termoelétrica de energia. Durante a queima do combustível, geralmente de origem fóssil, são emitidos poluentes atmosféricos gasosos, tais como os como de óxidos de enxofre ( $\mathrm{SOx}$ ) e nitrogênio (NOx), cinzas volantes e os materiais particulados (MP's) que se depositam no solo. Os MPs podem se deslocar na atmosfera depositando-se no solo em locais diferentes e distantes de onde foram gerados. Além disso, os $\mathrm{SO}_{\mathrm{x}}$ e $\mathrm{NO}_{\mathrm{x}}$ emitidos podem contribuir fortemente para a formação da chuva ácida e aumentarem ainda mais a corrosividade dos solos (SILVERS; HAKKARINEN, 1987).

Segundo Sandres (2004, apud DUTRA, A. C., NUNES, L. P,1991), no estudo de um processo corrosivo, utiliza-se comumente o valor de resistividade elétrica do solo como índice de sua agressividade.

Em um estudo preliminar, Ávila et al. (2016) foram determinadas as resistividades de solos de municípios da Região da Campanha Rio Grande do Sul (RS), conhecidamente afetados pelas emissões de uma Usina Termoelétrica (UTE). Após a medida da resistividade elétrica dos solos, determinou-se o grau de agressividade quanto a corrosividade: Candiota (muito corrosivo), Aceguá, Bagé e Hulha Negra (corrosivo), Dom Pedrito (moderadamente corrosivo) e Pinheiro Machado (não corrosivo).

No trabalho acima citado, atribuiu-se a alta corrosividade do solo do munícipio de Candiota à proximidade da UTE e também devido a este ser constituído por partículas pequenas, o que contribui para uma alta taxa de retenção de água e aeração e drenagem baixas.

Como sequência do estudo, neste trabalho avaliou-se o grau de corrosividade destes solos a um aço galvanizado (zincado), comumente utilizado em torres de LTs. Amostras deste material foram enterradas nos solos e monitorou-se, periodicamente, a agressividade ao material metálico. Foram realizados ensaios acelerados, em laboratório e ensaios em campo. Os testes acelerados tiveram como objetivo simular condições mais próximas do comportamento da corrosão esperado em campo.

\section{METODOLOGIA (MATERIAIS E MÉTODOS)}

Para os ensaios acelerados (laboratoriais), foram preparados corpos de prova (cupons) de aço galvanizado com área de aproximadamente $2 \mathrm{~cm}^{2}$. Nestes cupons foi criado um defeito artificial em formato de "X" (KLUNK; DICK, 2010) e posteriormente foram enterrados em solos contendo $25 \%$ em massa de cinzas volantes, como mostram as figuras 1-a) e 1-b).

Figura 1: (a) Cupon de aço galvanizado com defeito artificial (b) aparato experimental dos ensaios laboratoriais.
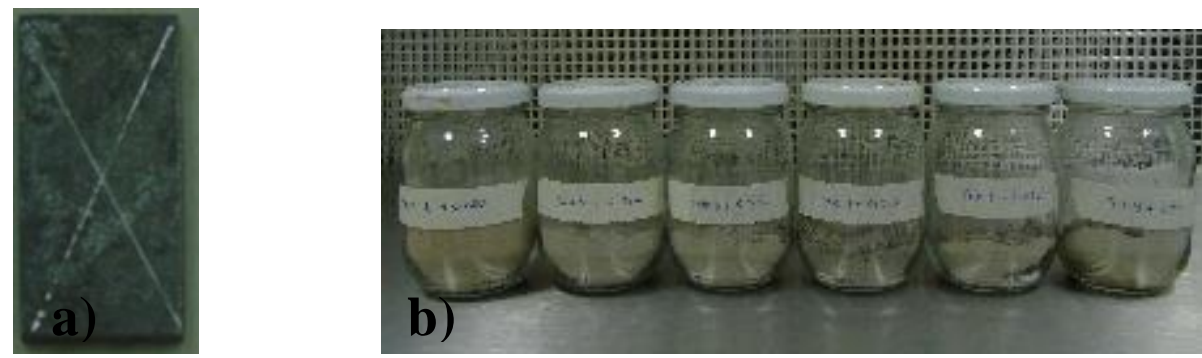
Para o ensaio em campo, a amostra metálica (aço galvanizado), foi enterrada, parcialmente na região central do município de Bagé, como mostra a figura 2.

Figura 2: amostra metálica parcialmente enterrada.

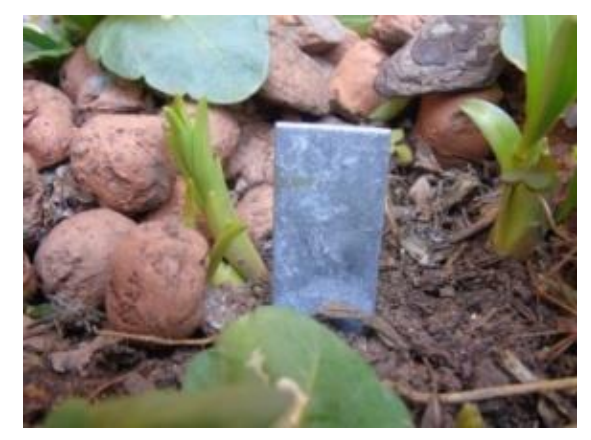

No estudo, foram avaliados seis solos da Região da Campanha Rio Grande do Sul, coletados nos municípios de Candiota, Aceguá, Bagé, Hulha Negra, Dom Pedrito e Pinheiro Machado previamente caracterizados quanto à corrosividade, conforme descrito em Ávila et al. (2016). Foram feitas aquisições de imagens, com câmera digital e estereomicroscopia, medidas de variação da massa, com balança analítica, e espessura com paquímetro digital, periódicas de forma a monitorar possíveis casos de corrosão nas amostras de aço galvanizado.

\section{RESULTADOS E DISCUSSÃO}

Foram observados indícios de corrosão localizada, de coloração levemente alaranjada, nos cupons enterrados nos solos de Candiota (Figura 3-a) e Bagé (Figura 3-b). O produto de corrosão alaranjado está relacionado à oxidação do aço sob o revestimento, como indicado (circulado) nas Figuras.

Figura 3-a: amostra metálica enterrada no solo de Candiota com indícios de corrosão
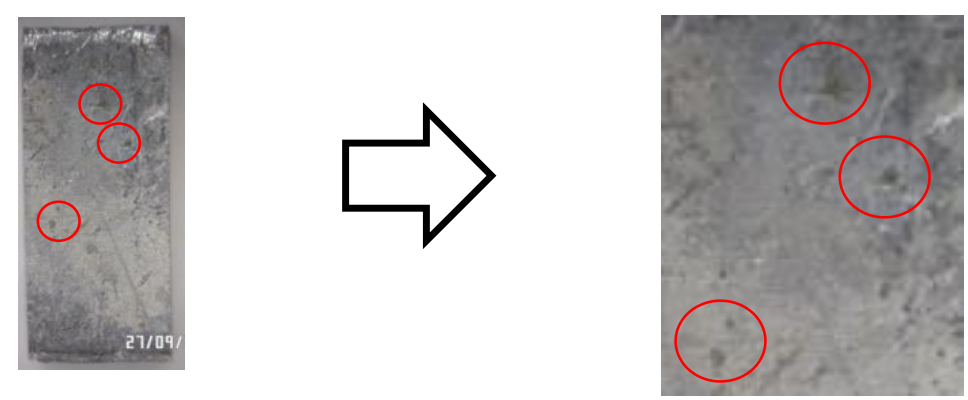
Figura 3-b: amostra metálica enterrada no solo de Bagé com indícios de corrosão
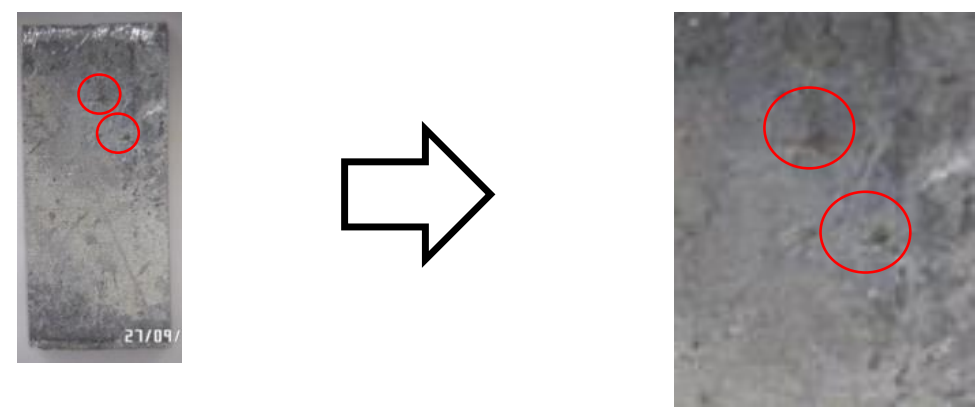

Em todos os cupons enterrados em amostras de solo com cinzas volantes (Figura 4a-c), verificou-se a presença de "corrosão branca", referente a um tipo de produto de corrosão que afeta superfícies galvanizadas, caracterizada pelo acúmulo de produto de corrosão composto de óxidos/hidróxidos de zinco (GENTIL, 2011). A corrosão branca foi mais intensa nas amostras enterradas nos solos dos municípios de Candiota (4-a) e Bagé (4-b), sendo menos acentuada nos demais, conforme mostra a Figura 4c para a amostra enterrada no solo de Dom Pedrito. A etapa seguinte à corrosão branca é a rápida corrosão do aço (GENTIL, 2011).

Figura 4-a, b, c: amostras metálicas de ensaios acelerados enterradas nos solos de Candiota, Bagé e Dom Pedrito com indícios de corrosão.
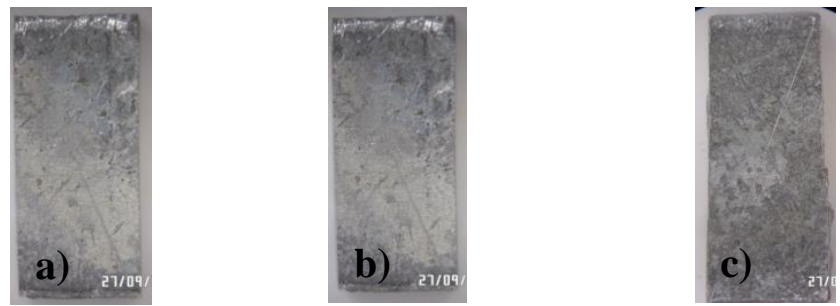

Para o cupon parcialmente enterrado em campo, observou-se corrosão branca e corrosão localizada na parte da amostra que estava enterrada (Figura 5). Quando ocorrem falhas ou porosidades nos revestimentos zincados, o zinco $(\mathrm{Zn})$ funciona como ânodo e a superfície do aço exposta ao meio corrosivo é protegida catodicamente.

Figura5: amostra metálica parcialmente enterrada em campo com indícios de corrosão branca e localizada.
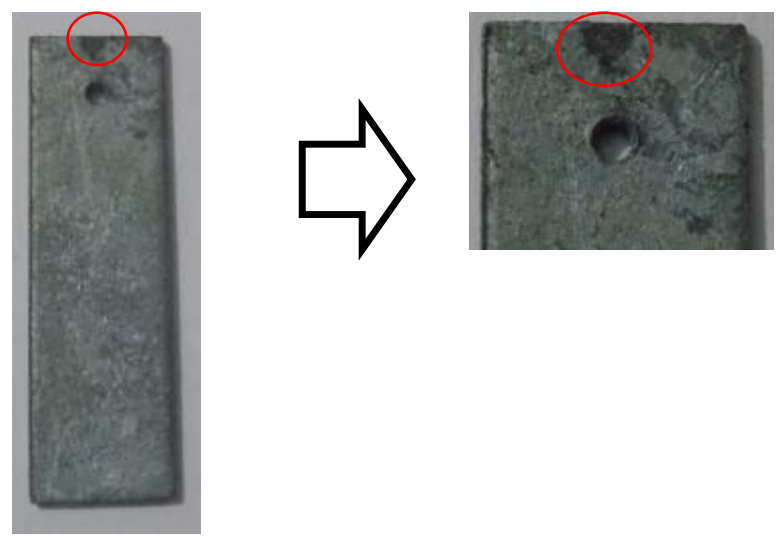
Nas análises de variação de massa e espessura das amostras, constatou-se que estas não foram significativas no período de estudo.

\section{CONCLUSÃO}

A partir dos resultados obtidos pode-se inferir que os solos em estudo são agressivos ao aço galvanizado. Esse fato é evidenciado pela formação de produtos de corrosão branca na superfície das amostras metálicas. Sendo assim, os resultados concordam com a análise preliminar realizada, indicando que o solo do município de Candiota é o mais agressivo às amostras durante o período de estudo (30 dias). Isso ocorre, possivelmente, em decorrência das alterações físico-químicas do solo advindas da deposição das emissões da UTE. Também foi observado que há tendência à corrosão em locais distantes da fonte emissora (UTE), porém de forma menos intensa.

\section{REFERÊNCIAS}

DUTRA, A. C., NUNES, L. P. Proteção catódica: técnica de combate à corrosão. Rio de Janeiro: Técnica LTDA, 1991. 207p.

GENTIL, V. Corrosão.3.ed.Rio de Janeiro: Livros Técnicos e Científicos. 1996. 345p.

GENTIL, V. (2011) Corrosão. Rio de Janeiro: Guanabara Dois.

SANDRES, C, A. Contaminação dos solos e águas subterrâneas provocada por vazamentos de gasolina nos postos de combustíveis devido à corrosão em tanques enterrados. 2004. 147f. Tese (Mestrado em Gestão de Segurança do Trabalho)- Universidade Federal Fluminense, Niterói. 2004.

RAMANATHAN, L. V. Corrosão e seu controle. Brasil: Hemus.339p.

KLUNK, M.; DICK, L. P. F. Estudo da corrosão em grelhas enterradas no solo em torres de linha de transmissão de energia elétrica. Relatório Técnico. Universidade Federal do Rio Grande do Sul. Porto Alegre, 2010. 